\title{
PERTUSSIS: ENFERMEDAD REEMERGENTE
}

\author{
BEATRIZ PESCADOR VARGAS ${ }^{1}$, LAURA ALEJANDRA ROA CULMA ${ }^{2 *}$ \\ ${ }^{1}$ Magister en Biología, Docente Asociada Facultad de Medicina \\ Universidad Militar Nueva Granada \\ ${ }^{2}$ Bióloga egresada de la Universidad del Tolima
}

*Correspondencia: lauraroac14@gmail.co

Recibido: 3 Febrero 2017 Aceptado: 12 Junio 2017

\begin{abstract}
RESUMEN
Introducción: Actualmente a pesar de las estrategias de vacunación a nivel mundial, B. pertussis se ha convertido en un problema de salud pública, sigue siendo una de las enfermedades menos prevenibles por vacunación en todo el mundo, aún en países desarrollados con amplia cobertura de vacunación.

Objetivo: Describir los principales mecanismos de virulencia asociados a la infección mediante los cuales la bacteria logra evadir la respuesta inmune, además de dar a conocer un panorama actual del estado de inmunización contra la tos ferina y la problemática de su reemergencia a nivel mundial.

Métodos: Se realizó una revisión mediante búsqueda electrónica de literatura; entre las estrategias de búsqueda se destaca el empleo de las bases de datos como PubMed, ScienceDirect, SciELO, Redalyc; y búsqueda en portales de salud; sobre aspectos generales de la enfermedad y su agente causal, además de últimas actualizaciones sobre el tema.

Resultados: Como lo confirman recientes estudios, el incremento del riesgo de infección por $B$. pertussis sigue presentándose en adolescentes y adultos debido a la disminución en la respuesta inmune inducida por la vacunación y la infección natural, por ende, la información actual indica que está reemergiendo la tos ferina en todo el mundo, situación que es necesario conocer para un oportuno diagnóstico y tratamiento.

Conclusiones: Análisis de la literatura demuestra la necesidad de ampliar el uso de técnicas moleculares; llevar a cabo la modificación de los programas de vacunación, con la administración de dosis de refuerzo entre adolescentes y adultos; además programas de monitoreo epidemiológico eficaces de recolección de casos con tos ferina y sistemas adecuados de notificación para lograr la reducción equitativa y sustentable de la morbilidad y mortalidad de ésta enfermedad.
\end{abstract}

Palabras clave: Bordetella pertussis; Adenylate cyclase toxin-hemolysin; cAMP intoxication; Pertussis vaccine; Genetic changes Bordetella pertussis.

\section{PERTUSSIS: REEMERGING DISEASE}

\begin{abstract}
Introduction: Currently despite vaccination strategies worldwide, B. pertussis has become a public health problem, it remains one of the least vaccine preventable diseases in the world, even in developed countries with extensive coverage of vaccination.
\end{abstract}


Objective: To describe the main mechanisms of virulence associated with the infection through which the bacterium manages to evade the immune response, as well as to present a current picture of the state of immunization against pertussis and the problem of its reemergence worldwide.

Methods: Electronic literature search was performed; among the search strategies we highlight the use of databases such as PubMed, ScienceDirect, SciELO, Redalyc; and search in health portals; on general aspects of the disease and its causal agent, in addition to the latest updates on the subject.

Results: As confirmed by recent studies, the increased risk of $B$. pertussis infection continues to occur in adolescents and adult's due to the decrease in the immune response induced by vaccination and natural infection, therefore, current information indicates that reemerging whooping cough around the world, a situation that is necessary to know for a timely diagnosis and treatment.

Conclusions: Analysis of the literature demonstrates the need to expand the use of molecular techniques; to carry out the modification of the vaccination programs, with the administration of doses of reinforcement between adolescents and adults; In addition to effective epidemiological monitoring programs for the collection of pertussis cases and adequate notification systems to achieve an equitable and sustainable reduction in the morbidity and mortality of this disease.

Key words: Bordetella pertussis; Adenylate cyclase toxin-hemolysin; CAMP intoxication; Pertussis vaccine; Genetic changes Bordetella pertussis.

\section{PERTUSSIS: DOENÇA REEMERGENTE}

\section{RESUMO}

Introdução: Atualmente, apesar das estratégias de vacinação em todo o mundo, $B$. pertussis tornou-se um problema de saúde pública, continua a ser uma das doenças menos evitáveis pela vacina no mundo, mesmo em países desenvolvidos com ampla cobertura de vacinação.

Objetivo: Descrever os principais mecanismos de virulência associados à infecção através dos quais a bactéria consegue evadir a resposta imune, bem como apresentar uma imagem atual do estado da imunização contra a tosse convulsa e o problema da ressurgência em todo o mundo.

Métodos: Pesquisa eletrônica de literatura foi realizadantre as estratégias de Investigação, destacamos o uso de bancos de dados como PubMed, ScienceDirect, SciELO, Redalyc; e investigação em portais de saúde; sobre aspectos gerais da doença e seu agente causal, além das atualizações mais recentes sobre o assunto.

Resultados: Conforme confirmado por estudos recentes, o aumento do risco de infecção por $B$. pertussis continua a ocorrer em adolescentes e adultos devido à diminuição da resposta imune induzida por vacinação e infecção natural, portanto, informações atuais indicam que a ressurreição de tosse convulsa ao redor do mundo, uma situação que é necessário conhecer para um diagnóstico e tratamento oportunos.

Conclusões: A análise da literatura demonstra a necessidade de ampliar o uso de técnicas moleculares; para realizar a modificação dos programas de vacinação, com a administração de doses de reforço entre adolescentes e adultos; além de programas efetivos de monitoramento epidemiológico para a coleta de casos de tosse convulsa e sistemas de notificação adequados para alcançar uma redução sustentável e equitativa na morbidade e mortalidade desta doença.

Palavras-chave: Bordetella pertussis; Adenilato ciclase-toxina-hemolisina; Intoxicação CAMP; Vacina contra a tosse convulsa; Alterações genéticas Bordetella pertussis. 


\section{Introducción}

La tos ferina, también llamada coqueluche o tos convulsiva es una enfermedad respiratoria de notificación obligatoria y prevenible por vacuna, que afecta a todos los grupos de edad especialmente a menores de un año. Su agente causal se relaciona al género bacteriano Bordetella, cuya principal especie implicada es el B. pertussis, sin embargo, se pueden identificar otras especies como $B$. parapertussis, B. holmesii y B. bronchiseptica este último conocido como un patógeno animal pero que rara vez puede infectar a personas inmunocomprometidas (1). El Síndrome coqueluchoide a diferencia de la tos ferina es un término que se ha utilizado para incluir aquellos pacientes que presentan un cuadro clínico indistinguible de tosferina, con diferentes etiologías infecciosas o no infecciosas. Los agentes involucrados pueden incluir virus $y$ bacterias, entre los que destacan Haemophilus influenzae, Moraxella catarrhalis, Mycobacterium pneumoniae, Adenovirus, Influenza virus, Parainfluenza 1-4, Virus sincitial respiratorio, citomegalovirus y virus de Epstein Barr (1,2).

Bordetella pertussis es un cocobacilo Gram negativo, capsulado, inmóvil, aerobio facultativo que tiene al ser humano como único reservorio. Las diferentes especies comparten un elevado grado de homología en el ácido desoxirribonucleico (ADN) entre los genes relacionados con la virulencia. Tan solo $B$. pertussis expresa la toxina de la tos ferina o toxina pertussis (TP), la cual es considerada la proteína más virulenta. La división en serotipos depende de los aglutinógenos termolábiles $\mathrm{K}$ y de los 14 existentes, 6 son específicos de B. pertussis. Los serotipos cambian según la región geográfica y a lo largo del tiempo (1).

B. pertussis produce una serie de sustancias activas biológicamente, muchas de las cuales juegan un papel importante en la enfermedad, la inmunidad y su forma de transmisión. Con respecto a esta ultima caracteristica, se ha documentado que, en la exposición a aerosoles, la hemaglutinina filamentosa y la pertactina son importantes elementos de anclaje a las células del epitelio respiratorio ciliado (3).

La tos ferina es una enfermedad muy contagiosa, con tasas de ataque de hasta el $80 \%$ en personas susceptibles. Esta patología ocupa el quinto puesto en las causas de muerte prevenible por vacunas en menores de 5 años, según datos de la Organización Mundial de la Salud (OMS) (4). Actualmente representa una reemergencia mundial por múltiples causas como: mayor reconocimiento de la enfermedad en la comunidad médica, sospecha clínica en adultos, mejor vigilancia del evento, el uso de técnicas moleculares en el diagnóstico, coberturas de vacunación no adecuadas, eficacia de la vacuna, ausencia de refuerzo en población adolescente y adulta, cambios genéticos del agente causal, entre otras; de ahí que resalta la importancia de su oportuno diagnóstico y tratamiento.

\section{Método}

Se realizó una revisión bibliográfica sobre los aspectos epidemiológicos, clínicos y moleculares que engloban tanto la tos ferina como su agente causal, Bordetella pertussis, mediante la búsqueda electrónica de literatura empleando bases de datos como PubMed, ScienceDirect, SciELO, Redalyc; y búsqueda en portales de salud, utilizando las palabras clave: "Bordetella pertussis", "Adenylate cyclase toxin-hemolysin", "cAMP intoxication", "Pertussis vaccine", "Genetic changes Bordetella pertussis". Se incluyeron artículos escritos tanto en inglés con en español; se seleccionaron un total de 79 artículos de los cuales 69 fueron obtenidos de PubMed; 6 obtenidos de ScenceDirect; 2 artículos desde SciELO; 2 obtenidos de Redalyc. Ademas se incluyó información de portales web de centros de referencia internacional en epidemiología como Centers for Disease Control and Prevention (CDC), World Health Organization (WHO).

\section{Resultados}

\section{Epidemiología}

Hipócrates, desde el año 400 A.C. denominó "quintas" a accesos de tos característicos del proceso; en 1578 se produjo una primera descripción clínica en relación con una epidemia en París. En 1669 se realizó la descripción de síndrome tos ferinoso como pertussis (tos severa) y en 1906 Bordet y Gengou lograron el aislamiento del agente Bordetella Pertussis de expectoraciones de niños y diseñaron una relación entre la sintomatología y el agente etiológico; en 1916 se recomendó el examen de placa tosida y en 1964 se produjo la demostración de los adenovirus tipo 2 como agentes de sindrome tos ferinoso, pertusoide o coqueluchoide; en 1966 Collier y otros describieron manifestaciones clínicas semejantes a la tos ferina en dos hermanos, aislando el adenovirus tipo 5 y llamando este cuadro síndrome pertussis; en 1975 Islur y otros hicieron referencia a un sindrome de tos ferina en 201 niños, en 139 de ellos se aisló B. Pertussis junto con adenovirus, y en los restantes 62 pacientes, 
encontraron adenovirus lo que ratifica lo establecido por Klenk y otros tres años antes, acerca de que una infección mixta bacteriana y viral pudiera estar presente en el síndrome tosferinoso o coqueluchoide $(5,6)$.

Sin embargo, alrededor de 1974 los ingleses, dejaron bruscamente de confiar en la vacuna contra la tos ferina e interrumpieron la vacunación, a raíz de la muerte de varios niños de corta edad; muchos médicos aconsejaron a los padres la no vacunación de sus hijos argumentando la escasa fiabilidad de la vacuna. Hasta entonces más del $85 \%$ de la población vacunaba a sus hijos; aquel año y los años siguientes la cifra descendió al 65\%. La enfermedad, que prácticamente había desaparecido, volvió a resurgir y dos grandes epidemias, en 1978-1979 y 1982-1983, causaron miles de víctimas (7).

A pesar de esto, los resultados de la reunión internacional celebrada en Copenhage durante 1988 confirmaron la gran utilidad de la vacunación contra la tos ferina. Confirmando su eficacia por el hecho de que un aumento de la tasa de vacunación, no se produjo la epidemia prevista para 1986. $(8,9)$.

Actualmente a pesar de las estrategias de vacunación a nivel mundial, $B$. pertussis se ha convertido en un problema de salud pública y sigue siendo una de las enfermedades menos prevenibles por vacunación en todo el mundo, aún en países desarrollados con amplia cobertura de vacunación; el 95\% de los casos de tos ferina ocurren en países de medianos y bajos ingresos con un estimado de 16 millones de casos y 200.000 muertes a nivel mundial cada año (10). En la última década se ha presentado un aumento en la incidencia de la enfermedad en países desarrollados, reportándose epidemias en Europa, Australia y Estados Unidos $(11,12)$.

Estudios posteriores revelan que ni la infección, ni la vacunación inducen una inmunidad protectora, ocasionando reinfecciones frecuentes en cualquier época de la vida, siendo los infantes menores de un año el grupo más afectado, con una mayor proporción de casos en menores de 6 meses que aún no han sido vacunados o no han completado el esquema de vacunación primaria (13).

La tos ferina es una infección reemergente en países con amplia cobertura de inmunización a infantes; de acuerdo al Centro de Control y Prevención de enfermedades, Estados Unidos experimentó en el año 2012 el brote de tos ferina más grande reportado en los últimos 50 años, con más de 48000 casos reportados a escala nacional $(14,15)$.
La reemergencia de la tos ferina puede ser atribuida a diferentes factores, entre éstos, cambios a nivel genético en las cepas circulantes de B. pertussis, una mayor circulación bacteriana entre los adolescentes y adultos, relacionado con una disminución en la inmunidad (16).

La disminución de la inmunidad inducida por la vacuna ha desplazado el pico de incidencia en los neonatos hacia los adolescentes y adultos; por otro lado, los brotes nosocomiales de la enfermedad no son infrecuentes y los trabajadores en el cuidado de la salud al ser expuestos se convierten en fuente de infección especialmente a infantes con pobre desarrollo inmunológico, como es el caso de los neonatos prematuros $(17,18)$.

Los programas de vacunación para adultos aún no han sido implementados en muchos países; se ha demostrado que las infecciones en adultos pueden ser debido a un esquema de vacunación incompleta en la niñez, ya que éstos se van volviendo susceptibles a las infecciones a medida que aumentan la edad, además, la probabilidad de encontrar anticuerpos inducidos por la vacunación desde la infancia disminuye con el tiempo. En un estudio reciente realizado por Oksuz et al., se determinó la positividad de anticuerpos IgG anti-pertussis por el método ELISA en adultos, encontrando el $60,4 \%$ de la población en estudio negativos, y el 39,6 \% positivos, de estos últimos, el 47,6\% pertenecían al grupo de edad de los 51-65 años, estudios como estos recomiendan la implementación de una dosis única de la vacuna contra la tos ferina para adultos con el fin de disminuir las fuentes de infección en infantes susceptibles (19).

Los neonatos a menudo contraen la infección por parientes infectados, miembros del hogar o personal del cuidado de la salud, quienes carecen de síntomas típicos; éstos últimos son los responsables de la mayoría de brotes reportados por tos ferina, ocasionando un impacto sobre neonatos, infantes hospitalizados y colegas; frente a esto, la restricción de visitantes, el uso de medicamentos inhalados y la vacunación a los trabajadores sanitarios se proponen como mecanismos eficaces contra la transmisión de la enfermedad, logrando evitar brotes intrahospitalarios, además de la identificación temprana de un posible paciente fuente (20).

De acuerdo a lo anterior, en un estudio reciente, en el cual se realizó detección serológica de $B$. pertussis en personal encargado del cuidado de la salud, se encontró que el $77 \%$ del personal no poseen anticuerpos contra la bacteria; y según otros estudios, solo un tercio de 
los niños de escuela primaria tiene anticuerpos frente a este microorganismo, que a su vez van disminuyendo en la población adolescente y adulta, lo cual se encuentra estrechamente relacionado con la reaparición de la enfermedad (21).

Por otra parte, entre el año 2008 y 2010 Urbiztondo y cols. reclutaron 460 trabajadores del cuidado de la salud de centros de atención primaria, con el fin de determinar la susceptibilidad a $B$. pertussis, midiendo anticuerpos IgG (anti-pertussis), en búsqueda de anticuerpos contra la toxina pertussis (PT) y la hemaglutinina filamentosa (FHA), obteniendo resultados positivos con más de una técnica específica, cuya prevalencia fue del $51 \%$, además de reportar títulos altos anti-PT en el $15 \%$ del personal seropositivo demostrando su reciente contacto con $B$. pertussis $(13,22)$.

\section{Clínica de la enfermedad}

La tos ferina es altamente contagiosa y puede esparcirse rápidamente de persona a persona mediante el contacto con aerosoles producidos al toser o estornudar por el individuo infectado, cuya bacteria se aloja inicialmente en la nasofaringe (23).

De acuerdo a estudios de enfermedades infecciosas, para valorar la transmisión de una enfermedad se tiene en cuenta el número reproductivo básico $\left(\mathrm{R}_{0}\right)$, el cual estima la velocidad con que una enfermedad puede propagarse en una población; teniendo en cuenta el $\mathrm{R}_{0}$, la tos ferina es considerada una enfermedad infecciosa más contagiosa que el polio, sarampión, rubeola, paperas y difteria; en la que una persona infectada puede transmitir la bacteria a otros 12-17 individuos susceptibles $(24,25)$.

En pacientes infectados con $B$. pertussis, se presenta un periodo de incubación usualmente entre 7-10 días, sin embargo, pueden llegar a presentarse hasta por 4 semanas. Esta enfermedad se caracteriza por accesos incontrolables de tos, acompañados de sibilancias respiratorias; a pesar de esto, la manifestación de signos y síntomas pueden variar dependiendo si se presenta en lactantes o adolescentes; en lactantes y niños hasta los 9 años, puede manifestarse como una enfermdad asintomática, hasta una presentación severa del tracto respiratorio superior con tos persistente y progresiva contínua durante semanas o meses (26).

Los síntomas clásicos consisten en tos rápida y violenta con la consecuente expulsión de aire de los pulmones, seguida de una inspiración intensa y ruidosa provocada por el espasmo de la glotis. El curso clínico de la enfermedad progresa a través de tres estadios consecutivos después de la infección y la incubación: estadio catarral, paroxístico y de convalecencia; cada uno de ellos con una duración aproximada de 1-3 semanas, y el paciente no se recupera completamente sino hasta 2-3 meses después (27).

En la primera fase se produce la infección o colonización, en la cual la bacteria llega hasta las células ciliadas del revestimiento epitelial del aparato respiratorio, donde logra la multiplicación. En lactantes a menudo se presenta sin alteración de la temperatura corporal o con febrícula, malestar general, dolor faríngeo, congestión nasal, rinorrea, lagrimación, estornudos y tos seca leve. Durante este estadio, el diagnóstico es frecuentemente pasado por alto, ya que los signos y síntomas pueden ser comunes con otras enfermedades infecciosas de origen viral como rinovirus, coronavirus e influenza; y a menudo durante esta fase los pacientes son tratados de forma ambulatoria sin un diagnóstico preciso, convirtiéndose en focos de transmisión para los contactos familiares, en escuelas y jardines infantiles (28).

En un segundo estadio se resume la enfermedad propiamente dicha, producida por la secreción de toxina que ocasionan los sintomas de la tos ferina, caracterizados por accesos violentos de tos (5-10 tos/paroxismos) que pueden durar varios minutos seguido de gritos inspiratorios, asociado a cianosis, proptosis, protrusión de la lengua, producción de salivación espesa, lagrimación e ingurgitación de las venas del cuello (29).

Los paroxismos de tos se deben al efecto de la toxina que produce el espesamiento del moco, lo cual dificulta el paso de aire por la tráquea, bronquios y bronquiolos; bloqueando las vías respiratorias y provocando asfixia y la muerte; dichos paroxismos pueden ser desencadenados por estímulos como la risa, el llanto o la deglución; ocurren más frecuentemente en la noche y su frecuencia se incrementa durante la primera a segunda semana del estadio paroxístico, con su posterior disminución gradual. Durante esta fase los pacientes pueden manifestar emesis (emesis post-tusiva), fatiga y agotamiento respiratorio $(26,30)$.

En el tercer estadío, de convalecencia, los síntomas disminuyen en frecuencia, duración y severidad. Sin embargo, la tos no paroxística, leve y crónica, puede durar hasta 6 semanas. Al transcurrir esta fase, los pacientes 
ya han recibido terapia antibiótica y de soporte adecuados. La tos ferina puede ser altamente sospechada en casos de tos persistente por más de 3 semanas, independientemente si evidencia paroxismo (31).

Las complicaciones pueden suceder en todos los grupos de edad, pero más comúnmente en los lactantes quienes requieren hospitalización en aproximadamente el $50 \%$ de los casos; un 50-70\% experimentan apnea; $20-23 \%$ pueden presentar neumonía y el $12 \%$ manifiestan pérdida de peso. Entre las complicaciones vistas en adolescentes y adultos se incluye la apnea (27-44\%), pérdida de peso (3-33\%) e incontinencia urinaria (3$28 \%$ ). Por otro lado, han sido reportadas manifestaciones neurológicas que incluyen convulsiones, descritas en todos los grupos de edad, aunque son más comunes en los infantes (26).

\section{Virulencia de Bordetella pertussis}

B. pertussis causa una infección persistente del tracto respiratorio, que puede durar semanas o meses en los lactantes, y a menudo se asocia con infecciones secundarias y neumonía, ya que la bacteria ha desarrollado estrategias para sobrevivir y multiplicarse dentro de diferentes entornos tanto intracelulares como extracelulares (32).

La regulación y modulación en la expresión de los factores de virulencia de $B$. pertusis se genera principalmente en respuesta a cambios en las condiciones ambientales mediante un sistema de transducción de señales conformado por un sensor/activador (BvgAS: Bordetella virulence gene activador/sensor): las adhesinas, autotransportadores y toxinas, que son los principales factores de virulencia regulados por dicho sistema (33).

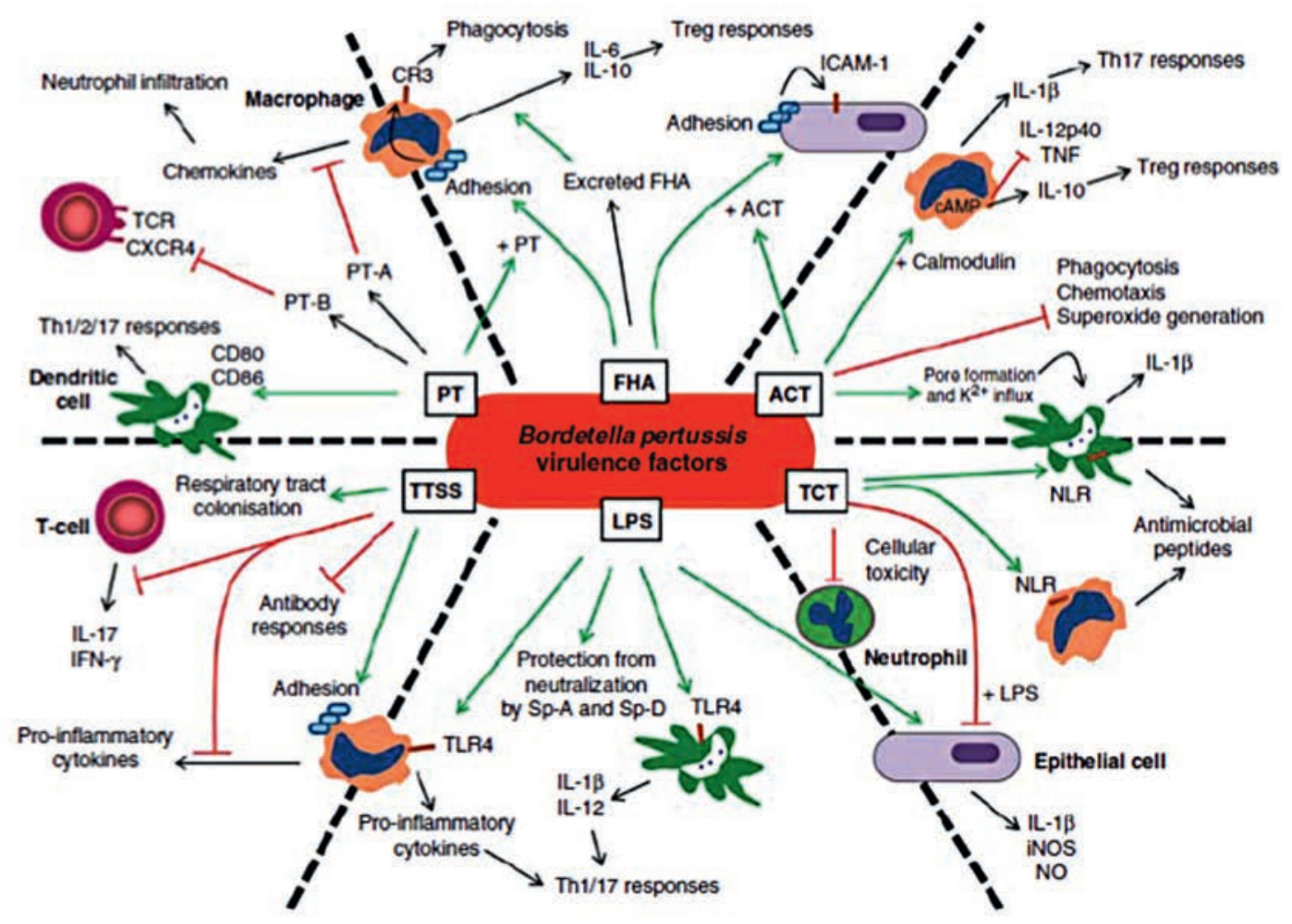

Figura 1. Efectos inmunomoduladores de los factores de virulencia de Bordetella pertussis. Este microorganismo cuenta con diferentes mecanismos para la evasión de la respuesta inmune del huésped, como factores de virulencia: Hemaglutinina filamentosa (FHA), toxina pertussis (PT), citotoxina traqueal (TCT), toxina adenilato ciclasa (ACT), sistema de secreción tipo III (TTSS) y lipopolisacáridos (LPS). Las flechas verdes indican un efecto regulador positivo hacia la célula blanco. Las líneas rojas indican un efecto modulador negativo en la célula. ICAM-1, molécula de adhesión intracelular 1; IL, interleuquina; iNOS, óxido nítrico sintetasa inducible; NLR, receptor de nucleótidos y dominio de oligomerización (NOD); NO, óxido nítrico; SP, proteína tensioactiva; TCR, receptor de células T; Th, T helper; TNF, factor de necrosis tumoral; Treg, células T reguladoras. Tomado de: Higgs R, Higgins S, Ross P, Mills K. Immunity to the respiratory pathogen Bordetella pertussis. Mucosal Immunology. 2012; 5(5):485-500. DOI:10.1038/mi.2012.54 PUBMED 
La invasión de la bacteria se produce por la adhesión a las células ciliadas del epitelio nasofaríngeo y del árbol traqueo-bronquial a través de moléculas de adhesión como: hemaglutinina filamentosa (FHA), fimbrias, pertactina (PRN) y otras proteínas de superficie, además de las toxinas secretadas: toxina pertussis (PT), citotoxina traqueal (CTT), toxina dermonecrótica (TDN) y la toxina adenilato ciclasa-hemosilina (ACT; CyaA), como factores importantes en su patogenicidad (34) (Figura 1).

B. pertussis es un patógeno no invasivo que causa infección limitada a la mucosa respiratoria; las manifestaciones sistémicas se deben a la acción de las toxinas secretadas como la toxina pertussis, la cual se encuentra relacionada con la adhesión y anclaje a los cilios respiratorios (26).

La toxina pertussis (PT) es un factor de virulencia secretado que consiste en un monómero A con actividad ribosiltransferasa de ADP, cataliza la transferencia de un grupo ADP-ribosil a las proteínas de unión a GTP reguladoras de las células el mamífero, impidiendo de esta manera la interacción del receptor acoplado en la membrana celular y su consiguiente comunicación intracelular; por otra parte, se compone de un oligómero $\mathrm{B}$, que se une a las glicoproteínas superficiales en una variedad de células huésped. La exposición a dicha toxina puede inhibir la función de varias células importantes del sistema inmune, incluyendo neutrófilos, macrófagos, monocitos y linfocitos (35).

La subunidad A inactiva proteínas $\mathrm{G}$ citoplasmáticas, inhibiendo varias vías de señalización de quimiocinas y conduce a la alteración de quimiotaxis de macrófagos, neutrófilos y linfocitos; por otro lado, el oligómero $\mathrm{B}$ activa varias moléculas de señalización asociadas a receptores de células $\mathrm{T}$, incluyendo Zap70 y la Proteína Cinasa C, lo cual promueve posteriormente la inmunosupresión mediante desensibilización cruzada del receptor de células $\mathrm{T}$ y le receptor de quimioquinas CXCR4 (36).

Esta toxina se compone de 5 tipos de subunidades, S1 (28 kDa), S2 (23kDa), S3 (22 kDa), S4 (11.7 kDa), y S5 (9.3 kDa). S1 demuestra la actividad enzimática de la toxina; las subunidades S2 a S5 forman el pentámero B. Dicha toxina ingresa a las células blanco por endocitosis y viaja por vía retrógrada a través del aparato de Golgi al retículo endoplasmático (RE). Del RE ingresa al citoplasma disfrazándose como una proteína huésped mal plegada y entrando en la vía de degradación asociada a RE; una vez en el citosol, la subunidad S1 cataliza la transferencia de Adenosina 5'Difosfato (ADP)-ribosa de la Nicotinamida Adenina Dinucleótido (NAD) a la subunidad inhibitoria alfa de la proteína $G(G i \alpha)$. La ADP-ribosilación de Gi previene la inhibición de la adenilato ciclasa y conduce a un aumento sostenido de la concentración intracelular de Adenosina Monofosfato Cíclico (cAMP) (37). (Figura 2.)

Por otro lado, la Toxina Adenilato Ciclasa (ACT; CyaA) está involucrada en la colonización temprana del tracto respiratorio. Esta toxina invade las células eucariotas y ocasiona sobreproducción de los niveles de cAMP, alterando la fisiología celular, con la supresión de la respuesta inmune del huésped llevando finalmente a la muerte celular (38).

La toxina cataliza la formación de niveles suprafisiológicos de AMPc, lo cual inhibe la función antibacteriana de los macrófagos y suprime la secreción de las citocinas inflamatorias IL-12p70 y TNF- $₫$ y promueve la secreción de IL-10, que junto con la IL-10 inducida por FHA, promueven el desarrollo de células Treg $\operatorname{Tr} 1$ antígeno-específicas, las cuales revierten la respuesta inmune del huésped y retrasan la eliminación bacteriana (39)

Además de sus funciones inmunomoduladoras, el dominio C-terminal promueven la formación de poros en la membrana de la célula diana, produciendo un flujo de $\mathrm{K}^{+}$, lo cual genera la formación y activación del complejo de inflamasoma NLRp3, que resulta en la activación de la caspasa-1 y la liberación de IL-1B desde las células dendríticas, citoquina importante en la protección del huésped y el aclaramiento bacteriano mediante la inducción de células Th17 (IL-17) (40).

Esta es una proteína bifuncional y toxina $A B$, pero a diferencia de las enterotoxinas AB5 como la PT, se compone de un único polipéptido de 1706 aminoácidos que presenta dos dominios; uno de ellos con actividad adenilato ciclasa $(\mathrm{AC})$ sensible a calmodulina $(\mathrm{CaM})$, ubicado dentro de los 400 aminoácidos próximos al extremo $\mathrm{NH}_{2}$-terminal; el otro dominio RTX (Repeat-in-ToXins) ó hemolítico (Hly) hace parte de los aminoácidos restantes (1306), involucrados en la unión de la toxina a las células diana y la entrada del dominio catalítico al citosol, además de promover la formación de poros en la membrana de las células diana (41).

Esta toxina pertenece a la familia de toxinas citoliticas formadoras de poros (hemolisina RTX), análoga a las toxinas citolíticas formadoras de poros dependientes de $\mathrm{Ca}^{+2}$, producidas por bacterias patogénicas gram 


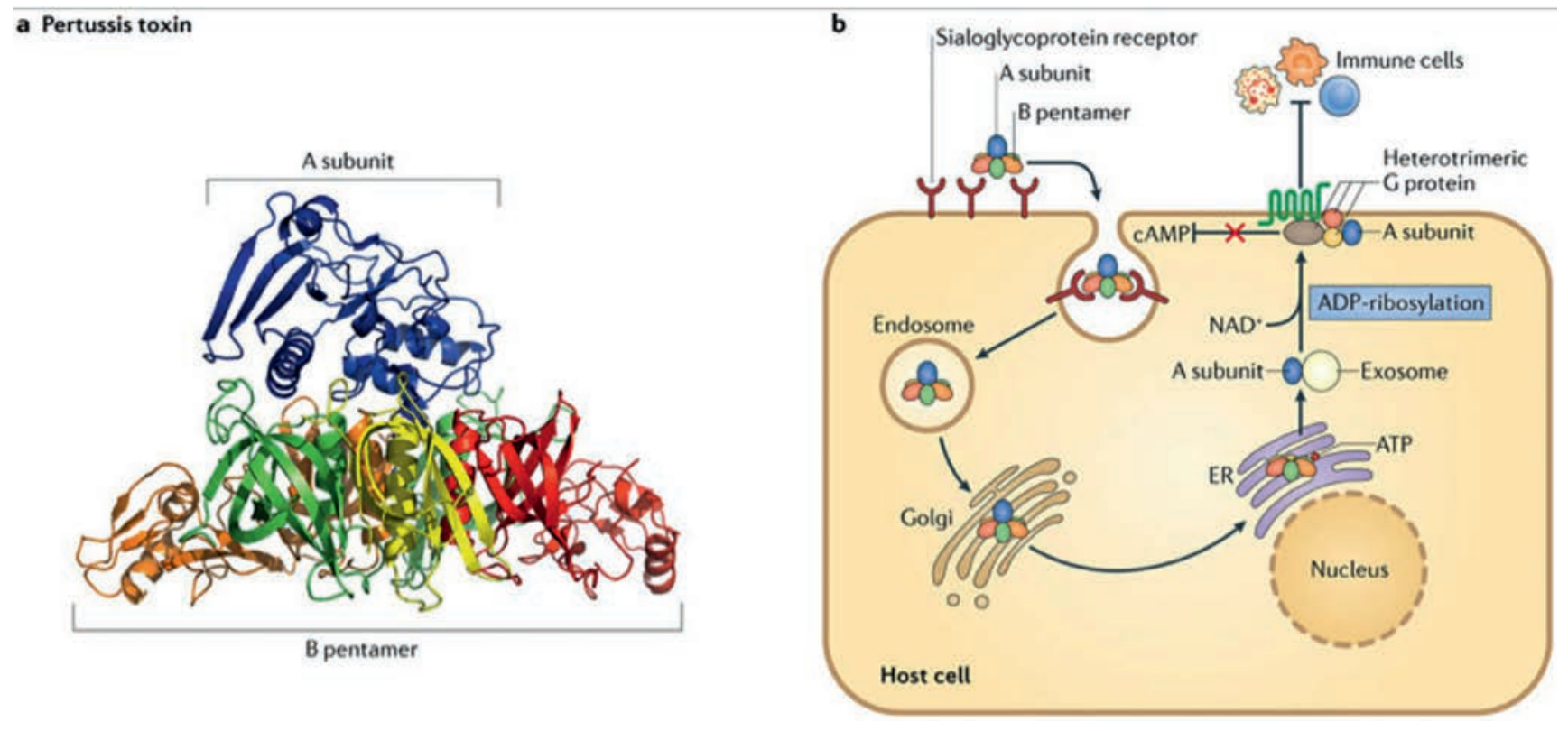

Figura 2. a. Toxina pertussis (PT; Protein Data Bank (PDB) acceso $1 P R T)$ : es una toxina tipo $A B_{5}$ compuesta por una subinidad catalítica (subunidad A) y un pentámero de unión a la membrana o subunidad transportadora (pentámero $B$ ). PT es ensamblada en el periplasma bacteriano y exportado por el sistema de secreción tipo IV. b. Después de la unión al receptor celular de sialoglicoproteina. PT es endocitada y llevada a través del apartato de Golgi y el Retículo endoplasmático (ER). En el ER, el pentámero $B$ se une al ATP y se disocia d ela subunidad A. Esta última, es luego transportada dentro del citoplasma y circula dentro de exosomas hasta la membrana plasmática, donde ocurre ADP-ribosilación de la subunidad-a de la proteina G heterotrimérica. Estas modificaciones alteran la habilidad de la proteina $G$ de regular múltiples rutas enzimáticas, incluyendo la habilidad de inhibir la formación de AMPc. El resultado conjunto de esas modificaciones es la supresión inicial de la producción de citoquinas inflamatorias y la inhibición del reclutamiento de células de la respuesta inmune al sitio de la infección. Tomado de: Bordetella pertussis pathogenesis: current and future challenges. Melvin J, Scheller E, Miller J, Cotter P. Nature. 2014: 12; $274-288$.

negativas, tales como la $\alpha$-hemolisina de Escherichia coli y leucotoxina de Pasteurella hemolítica (42).

El dominio catalítico de CyaA está compuesto a su vez por dos subdominios conocidos como $\mathrm{T}_{25}$ y $\mathrm{T}_{18}$; en ausencia de CaM, este dominio se encuentra en estado de desorden estructural, en el cual su estructura terciaria es compacta e hidratada; una vez que el dominio C-Terminal de la CaM interactúa con el subdominio $\mathrm{T}_{18}$ de la toxina, el extremo $\mathrm{NH}_{2}$-terminal adquiere una conformación extendida y deshidratada, proporcionándole cambios en sus propiedades hidrodinámicas (43).

Por otra parte, el extremo RTX (C-Terminal) de la toxina contiene el dominio de unión al receptor ( $\mathrm{RD}$, en los residuos 1006 a 1706); esta región es rica en aspartato y glicina, además de repeticiones en tandem de nonapéptidos de unión al calcio, lo cual es una de las características de la gran familia de toxinas citolisinas bacterianas conocidas como RTX (Repeat-in-ToXin). El dominio RD se caracteriza por un alto nivel de desorden estructural y cargas principalmente negativas, las cuales son parcialmente neutralizadas por la unión al calcio, lo cual favorece la transición del desorden, al orden estructural; por otro lado, el calcio induce el plegamiento del dominio RD requerido para la actividad biológica de la toxina (44).

Este dominio, RTX, puede subdividirse en 4 regiones: 1) una región en la que se ubican varios segmentos hidrofóbicos que se insertan en la membrana plasmática adoptando estructuras alfa-hélice, 2) otra región donde ocurre la palmitoilación de la Lys, 3) una región de 38 a 42 repeticiones de los motivos RTX, 4) una señal de secreción carboxi-terminal no procesada (45).

El extremo C-Terminal sufre un cambio conformacional en presencia de Calcio, en el cual varios motivos se pliegan formando hélice $\mathrm{B}$, y en cada giro $\mathrm{B}$, el Calcio se une al grupo carbonilo de la cadena lateral del aspartato; es necesaria la unión de 30 a 40 iones de Calcio para llevar a cabo el plegamiento y actividad de la toxina; la unión del calcio permite conservar la capacidad de la toxina frente a la permeabilización y actividad hemolítica de la 
forma monomérica de CyaA, hCyaAm, bajo un ambiente rico en dicho cofactor, además, la unión del dominio $\mathrm{C}$-terminal al calcio permite la fuerte estabilidad de regiones N-terminal (46).

El calcio es un cofactor esencial tanto para la toxina CyaA, como para los otros miembros de la familia de toxinas RTX; ya que se une a los segmentos repetidos RTX $y$ es de vital importancia para llevar a cabo las diferentes funciones de la toxina, incluyendo la secreción, la unión al receptor celular y/o membrana de la célula blanco, la formación de poros y actividad hemolítica, y finalmente para el ingreso del dominio catalítico de la toxina a través de la membrana plasmática (47).

La toxina adenilato ciclasa (ACT) se sintetiza como un precursor inactivo (proCyaA) codificado por el gen CyaA, que es convertido a su forma activa CyaA, ya que el dominio RTX alberga los sitios de activación, que se produce gracias a la palmitoilación de la Lisina 860 y Lisina 983 (Lys ${ }_{860}$; Lys ${ }_{983}$ ), mediada por la aciltransferasa CyaC. Estas dos modificaciones postraduccionales son esenciales para la actividad citotóxica de CyaA y también para el replegamiento de la toxina en un estado holo-monomérico ya que las acilaciones mejoran significativamente el rendimiento de recuperación de monómeros frente a oligómeros y multímeros (48).
CyaA penetra las células blanco mediante una serie de pasos: en una fase inicial dicha toxina se une a la superficie celular, posiblemente a gangliósidos, para lo cual es necesaria la integridad del extremo C-terminal de la toxina y de la palmitoilación de la Lys; dicho proceso de ingreso puede resumirse en tres pasos consecutivos que incluyen la inserción, la translocación y el clivaje intracelular; una vez la toxina es insertada en la membrana de la célula blanco, la porción $\mathrm{NH}_{2}$-terminal es translocada al otro lado de la membrana mediante la creación de un canal proteico por el dominio C-terminal de la toxina (49) (Figura 3).

Luego de ser secretada, el dominio $\mathrm{RD}$ se une de manera dependiente de calcio a la integrina CD11b/CD18 expresada en células mieloides, tales como macrófagos, células dendríticas, neutrófilos y células NK, siendo este tipo de células los principales blancos de la toxina CyaA in vivo (50).

Esta unión de alta afinidad se realiza principalmente al complejo CD11b/CD18, que pertenece a los receptores aMß2 de la subfamilia de receptores leucocitarios, conocidos como receptores de complemento-3 (CR3); sus cadenas $\alpha$ y $\beta$ equivalen a glicoproteínas transmembrana de $165 \mathrm{kDa}$ y $95 \mathrm{kDa}$ respectivamente, usualmente expresados en la superficie de células mieloides, ocasionando

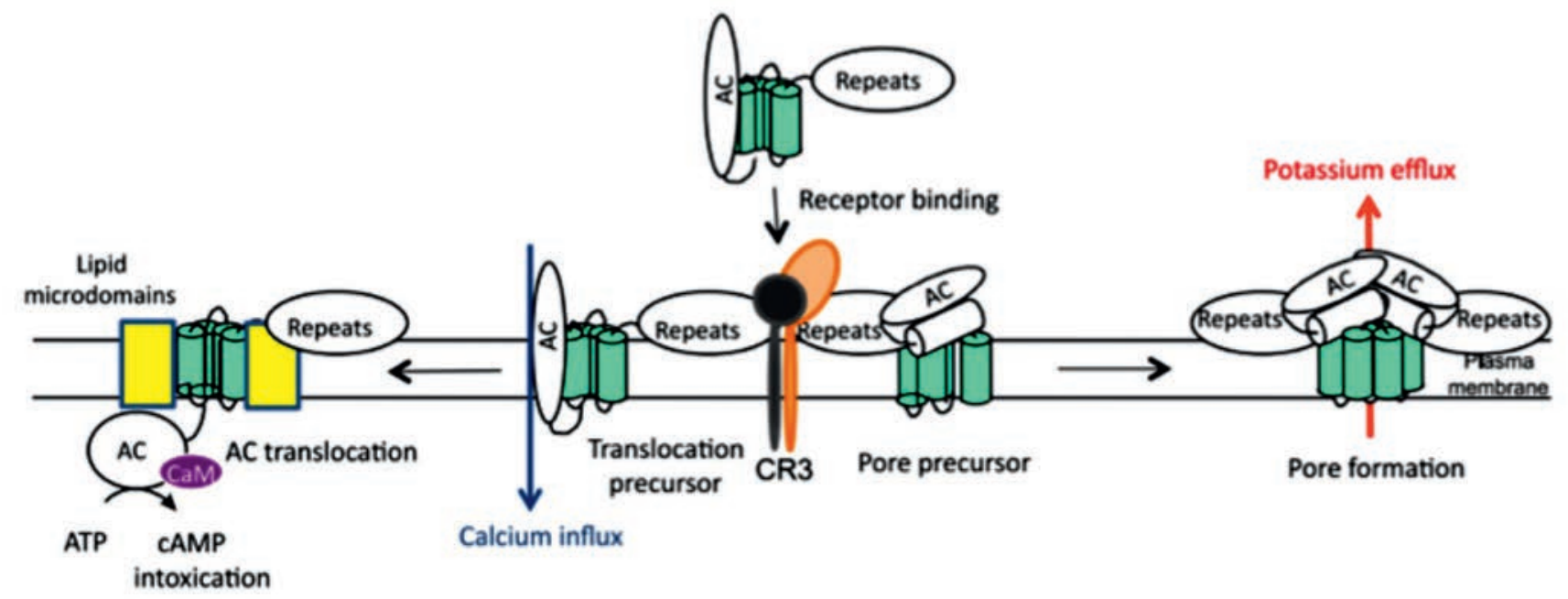

Figura 3. Representación esquemática de la función de CyaA. La invasión celular y la formación de poros por la toxina parecen ser funciones independientes, pero se efectúan en paralelo sobre la membrana de la célula blanco. La toxina está conformada por dos dominios, uno de ellos permite la translocación y la entrega de la región catalítica de la toxina a través de la bicapa lipídica, y a su vez provoca la afluencia concomitante de iones de calcio en las células. El otro dominio permite la formación del poro provocando el flujo de potasio en la célula diana que promueve liberación de IL-1凶. Tomado de: Masin J, Osicka R, Bumba L, Sebo P. Bordetella adenylate cyclase toxin: a unique combination of a pore-forming moiety with a cell-invading adenylate cyclase enzyme. FEMS Pathogens and Disease, 2015; 73(8): ftv075. 
que la función de dichas células efectoras de la respuesta inmune se encuentre alterada (51).

A pesar de que la toxina utiliza para su ingreso la vía principal a través de dicho receptor, ésta también puede ingresar a una gran variedad de células de forma independiente del mismo, a través de otros receptores específicos independiente de acilaciones post-translacionales de la toxina, o mediante la interacción directa gracias al potencial de membrana (52).

El dominio catalítico de la toxina es conducido hacia el citoplasma mediante la formación de un poro mediado por el dominio C-terminal, proceso llamado translocación o intoxicación, durante esta fase hay un incremento rápido de los niveles de cAMP; por otro lado, la entrada de la toxina es independiente de la acidificación de las vesículas endocíticas; estudios han demostrado que la toxina CyaA, tiene la capacidad única entre las toxinas enzimáticamente activas, de cruzar directamente la membrana citoplasmática de la célula y llegar al citosol sin necesidad de endocitosis; como se ha reportado in vitro, la toxina es capaz de penetrar con eficacia una variedad de tipos celulares incluyendo los eritrocitos de mamíferos que carecen de mecanismos de endocitosis de membrana $(46,53,54)$.

Una vez dentro de la célula, el dominio catalítico, es activado por la calmodulina y cataliza la conversión de ATP a cAMP, molécula clave que actúa como segundo mensajero provocando deterioro en las funciones bactericidas de los fagocitos como la quimiotaxis, la fagocitosis, o la producción de superóxido además de promover la apoptosis de los macrófagos (55-57).

La hemaglutinina filamentosa (FHA) son estructuras similares a bastones de aproximadamente 220.000 Da, que median la adhesión a las células ciliadas del epitelio respiratorio, a través de una integrina (RGD con secuencia arginina, glicina y ácido aspártico) (58), además de un dominio de reconocimiento a carbohidratos y de unión a heparinas se encuentra expresada en la superficie de la célula bacteriana, pero también es secretada al medio extracelular. Su papel en la adherencia al epitelio respiratorio se intensifica en presencia de ACT y balsas lipídicas de colesterol (59).

Por otro lado, promueve la fagocitosis de B. pertussis por los macrófagos y polimorfonucleares; además de su papel en la adherencia bacteriana y fagocitosis, también tiene importantes funciones inmunomoduladoras, inclu- yendo la producción de IL-6 e IL-10, la supresión de la producción de IL-12 por los macrófagos y CDs, lo cual conduce a la generación de células Treg y la producción consecuente de IL-10, a su vez, éste suprime la formación de IFN- y y por tanto inhiben la formación y función de células Th-1 (60).

La pertactina (PRN) es una proteína autotransportadora de la membrana externa de $69 \mathrm{kDa}$, la cual tiene un papel importante en la adherencia de B. pertussis a monocitos y células epiteliales; hace parte de las proteínas de membrana externa con motivo RGD y su expresión es modulada por el locus vir, el cual controla la expresión de los otros factores de virulencia bacteriana (61).

PRN es también un blanco importante para los anticuerpos inducidos tanto en la infección natural como por la vacuna, ya que es uno de los componentes de la mayoría de las vacunas acelulares en uso actual (62).

Sin embargo, investigaciones reportan aislados de $B$. pertussis con una baja producción de PRN en hallazgos realizados en diferentes países donde ha sido introducida la vacuna acelular (aP) contra la tos ferina. Recientes estudios han demostrado que las cepas deficientes en PRN colonizan el tracto respiratorio de forma más efectiva que las cepas productoras de la proteína, en ratones vacunados con la vacuna aP. Se ha demostrado que los aislamientos de la bacteria, que no producen PRN son capaces de mantener una infección más duradera en comparación con los aislados productores de la misma, en un modelo in vivo inmunizado con la vacuna aP; por tanto, la pérdida de la producción de PRN podría proporcionar una ventaja selectiva de estas cepas, lo que explica el aumento de dichos aislados en la población (63-65).

\section{Respuesta Inmune Del Hospedero}

B. pertussis cuenta con una gama de toxinas y otros factores de virulencia críticos para la invasión y producción de la enfermedad, los cuales son dianas antigénicas para anticuerpos y células T. Además de su replicación extracelular, lo hace también en células del epitelio respiratorio, de igual forma puede sobrevivir al interior de los macrófagos; lo anterior sugiere que tanto la inmunidad celular como la humoral son necesarias para la eliminación de la bacteria en el tracto respiratorio (41).

La bacteria se une a células del epitelio ciliado tanto de la tráquea, bronquios, bronquiolos y de manera intracelular 
se encuentra en células epiteliales ciliadas y macrófagos alveolares; los macrófagos infiltrados y residentes, son las primeras células de la respuesta inmune innata en detectar y responder a la infección; posteriormente es seguido por un flujo de neutrófilos, luego de células NK y finalmente de células $T \alpha / \beta$; en cuanto a la inmunidad humoral, la IgA secretora y la IgG han sido reportadas en experimentos de modelos murinos (41).

Modelos animales de infección por $B$. pertussis, así como estudios in vitro, han demostrado que la bacteria puede ingresar, sobrevivir y persistir en los macrófagos, sugiriendo que estas células permiten la propagación y la diseminación de la infección a nuevos huéspedes. Una alta proporción de bacterias fagocitadas son destruidas dentro de los compartimentos ácidos de los macrófagos, pero otra cantidad pueden evadir su destrucción y reproducirse (66).

A diferencia de los macrófagos, los neutrófilos no son buenos reservorios para $B$. pertussis, debido a su corta vida media, sin embargo, juegan un papel crucial en la fagocitosis bacteriana. A pesar de esto, los factores de virulencia permiten la evasión de esta respuesta y la supervivencia del microorganismo. La toxina pertussis parece modular la respuesta inmune temprana a $B$. pertussis, retrasando la infiltración de neutrófilos; del mismo modo la ACT puede inhibir la función de los neutrófilos por la disminución en su capacidad de fagocitosis, la generación de superóxido y la inhibición de la quimiotáxis (67).

Por otro lado, las CDs permiten la presentación de antígenos a las células $\mathrm{T}$ y proveen una fuente de citoquinas innatas que promueven la diferenciación de células $\mathrm{T}$ naive; el reconocimiento de los factores de virulencia de $B$. pertussis generan fuertes señales proinflamatorias que son cruciales para desencadenar la producción temprana de citoquinas y quimiocinas, seguido por la activación de la respuesta de células T (68).

Los lipopolisacáridos (LPS) bacterianos se unen a los Toll-like receptor 4 (TLR-4) en las CDs e incentivan su maduración y la secreción de IL-12 e IFN- $\mathrm{\gamma}$, que impulsa la inducción de células Th1, y éstas a su vez median el aclaramiento bacteriano. Además, la activación de CDs por la ACT, también promueve la inducción de células Th1. Los otros factores de virulencia como FHA, generan respuestas antiinflamatorias, incluyendo la producción de IL-10 por CDs, que conduce a la producción de células Treg, las cuales evidencian un papel protector esencial, ya que estudios han demostrado que la ausencia de cé- lulas Treg productoras de IL-10 aumentan la mortalidad mediada por excesiva inflamación en los pulmones ocasionada por la infección de B. pertussis (69) (Figura 4).

Estudios en modelos murinos muestran que los mecanismos de la respuesta inmune innata involucran células dendríticas (CDs), macrófagos, neutrófilos, células Natural Killer y péptidos antimicrobianos que ayudan al control de la infección; por otro lado, el aclaramiento bacteriano requiere de la respuesta inmune mediada por células. Investigaciones ha revelado diferencias mecánicas en el tipo de respuesta inmune celular inducida con los distintos tipos de vacunas: de células enteras (wP), como la acelular $(\mathrm{aP})$; la vacuna $\mathrm{wP}$, a pesar de su propensión a causar reacciones adversas en los receptores, es capaz de inducir una fuerte respuesta inmune celular; estudios en años recientes demuestran que tanto la infección natural como la vacuna $\mathrm{wP}$, inducen predominantemente respuesta vía Th1 con presencia de IFN-y e IL-17 por células Th17 en menor proporción; por el contrario, la vacuna $\mathrm{aP}$, induce principalmente respuesta Th2 y Th17, con una débil respuesta de Th1 (70).

Una inmunidad mediada por células Th17, es necesaria para brindar protección contra bacterias extracelulares ya que la IL-17 promueve el reclutamiento de neutrófilos (73). Por otro lado, se ha demostrado que el INF-y es necesario para el control de la infección en el tracto respiratorio, ya que los ratones que carecen de esta citoquina o de su receptor, desarrollan infección letal y diseminadora (41).

En un trabajo llevado a cabo por Ross et al., en el 2013, se demostró la contribución de las células Th1 y Th17 en la respuesta inmune adaptativa frente a $B$. pertussis, ya que ambos tipos de células permitieron la eliminación la infección primaria en ratones previamente vacunados con wP; y por otro lado, mediante el uso de la vacuna aP con sales de aluminio como adyuvante, logró inducir respuestas de tipo Th17 así como de tipo Th2. Se plantea que la respuesta mediada por Th17, requiere de la activación de señalización IL-1R en células de la inmunidad innata y su protección se asocia con el reclutamiento, activación y muerte celular a nivel pulmonar después de la estimulación con B. pertussis, mediado por neutrófilos (71).

Tradicionalmente se han aceptado las sales de aluminio (alumbre) como adyuvantes en las vacunas aP que aumentan la respuesta inmune a los antígenos de la vacuna y facilitan la retención del antígeno en el sitio de inyección promoviendo la respuesta de anticuerpos y la captación del antígeno por las células presentadoras para 
el posterior cebado de las células T en los ganglios linfáticos; por otro lado, se ha reportado que el alumbre promueve la respuesta celular tipo Th2, las cuales proveen la protección mediada por anticuerpos contra bacterias extracelulares; más recientemente, ha sido demostrada la función del alumbre en la activación del inflamasoma NLRp3, involucrado en la mediación de cambios conformacionales que permiten el reclutamiento de la proteína adaptadora ASC (apoptosis-asociated speck-like protein containing a caspase recruitment domain), impor-

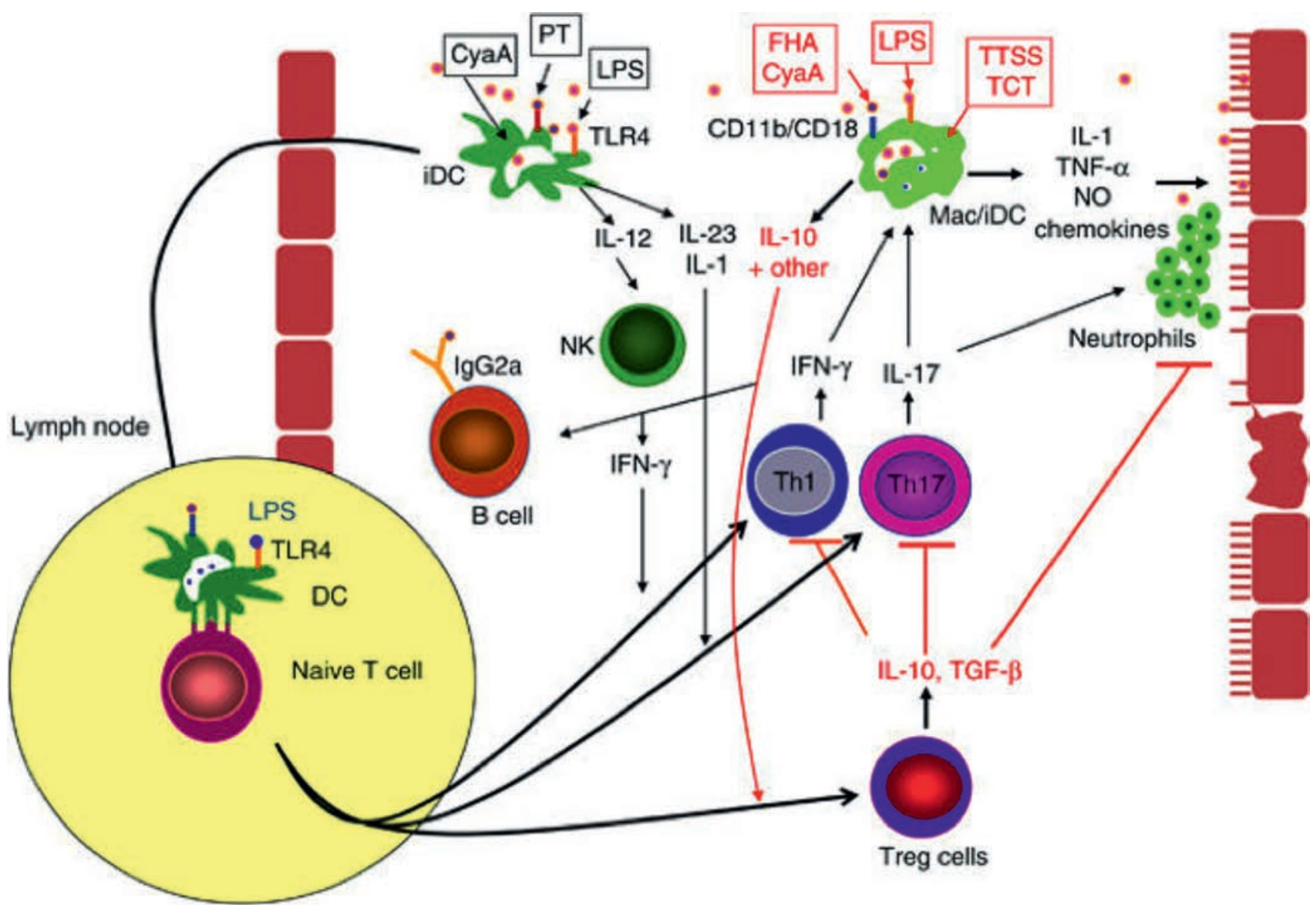

Figura 4. Respuesta inmune del hospedero frente a la infección por B. pertussis. Una vez B. pertussis ingresa en el tracto respiratorio, ésta se une a las células epiteliales ciliadas, donde migran células de la respuesta inmune innata, como macrófagos (Mac) y células dendríticas (iDC). Las DC presentan antígenos bacterianos a las células T. Se genera la producción de interleucina IL-12 por células de la respuesta innata y se impulsa la producción de células Thelper tipo 1 (Th1); la IL-1ß e IL-23 promueven la diferenciación de células Th17. Sin embargo, en la infección temprana, la acción de las células T locales es suprimida por células innatas que secretan IL-10 como respuesta a la hemaglutinina filamentosa (FHA), la toxina de adenilato ciclasa (ACT) y por la acción de las células T reguladoras (Treg). El óxido nítrico (NO) y las citoquinas pro-inflamatorias, IL-1 y el factor de necrosis tumoral TNF-a, son inducidos por toxinas bacterianas, especialmente lipopolisacárido (LPS), citotoxina traqueal (TCT), ACT y toxina pertussis (PT), que además contribuyen a la eliminación bacteriana, también median la patología pulmonar local y son responsables de muchas de las consecuencias sistémicas y neurológicas de la infección. El interferón (IFN) - y secretado tempranamente en la infección por células DC y natural killer (NK); de modo más tardío en la infección, las células Th1, estimulan el reclutamiento y la activación de macrófagos y neutrófilos. La IL-17 secretada por células Th17 promueve la producción de proteína 2 inflamatoria de macrófagos y el reclutamiento y activación de neutrófilos. Las bacterias opsonizadas o no opsonizadas son absorbidas por neutrófilos y macrófagos, que son destruidos por el NO o intermedios reactivos de oxigeno. Las flechas negras representan respuestas inmunes inflamatorias/efectoras y las flechas rojas representan respuestas antiinflamatorias e inmunosupresoras. TGF, Factor de Crecimiento Transformante; TLR4, Receptor tipo Toll 4. Tomado de: Higgs R, Higgins S, Ross P, Mills K. Immunity to the respiratory pathogen Bordetella pertussis. Mucosal Immunology. 2012; 5(5):485-500. DOI:10.1038/mi.2012.54 PUBMED 
tante para el reclutamiento y activación de caspasa-1, responsable de la maduración y obtención de las formas activas de IL-1 $\beta$ e IL-18 (72,73).

\section{Avances en inmunización}

La combinación triple de toxoides diftérico-tetánico y componentes de B. pertussis (células enteras o acelulares) es una de las vacunas más utilizadas en todo el mundo ( 131 países con una cobertura de $\geq 90 \%$ en 2012 ) en una serie primaria de 3 dosis y refuerzo en el segundo año de vida (74).

Frente a la necesidad de inmunizar adolescentes, además de proporcionar seguridad concerniente a la vacuna wP y problemas en su fabricación, condujo el desarrollo, autorización e introducción de vacunas acelulares contra la tos ferina (aP) en los años 90'. Esta vacuna reemplazó rápidamente la vacuna wP para la inmunización a recién nacidos, además de la inmunización de refuerzo para los adolescentes en países desarrollados y luego su introducción como refuerzo para los adultos. La aP está compuesta por proteínas purificadas de B. pertussis, en partirucular la toxina pertussis (PT), hemaglutinina filamentosa (FHA), pertactina (PRN) y agluninogenos finbriales FIM2 y FIM3. A comparación de otras vacunas, la protección eficiente de aP parece necesitar al menos tres antígenos en la formulación; estudios clínicos de la vacuna aP muestran que la eficacia de tres o más componentes vacunales es comparable con la vacuna $\mathrm{wP}$, mientras que uno o dos componentes fueron reportados menos eficaces (75-77).

Las últimas estrategias incluyen el uso de la vacuna acelular, la cual induce inmunidad específica contra pocos factores de virulencia entre los cuales la pertactina es incluida en tres de cinco componentes acelulares (78). A pesar de la efectividad de ésta, se ha reportado un incremento en la prevalencia de aislados $B$. pertussis no productores de PRN; en algunos países como Francia, se usa una vacuna $\mathrm{aP}$ de dos componentes que incluye la toxina Pertussis (PT) y la hemaglutinina filamentosa (FHA), o vacuna $\mathrm{aP}$ de tres componentes (aP-3), incluyendo PT, FHA y PRN; ésta última vacuna se utiliza para la inmunización de lactantes y adolescentes, en la cual una elevada proporción de la vacuna induce inmunidad dirigida frente a PRN (78).

Sin embargo, estudios han reportado que aislados clínicos deficientes en PRN, resisten la inhibición in vitro de la citotoxicidad celular cuando se incuban junto con anticuerpos específicos anti-PRN, lo cual podría ser una ventaja selectiva ya que los aislados deficientes en PRN, podrían resistir la actividad opsonofagocítica mediada por anti-PRN bajo dichas condiciones (79).

Uno de los interrogantes es si la falta de producción de pertactina podría ser beneficiosa in vivo, en inmunizaciones con aP-3 que promueva la formación de anticuerpos anti-PRN debido a los mecanismos antes mencionados (75). Estudios de evaluación de asociación entre la producción de PRN y la inmunización, sugieren que las personas vacunadas tienen una mayor susceptibilidad a las cepas deficientes en pertactina comparado con las cepas productoras; aquellas cepas deficientes en PRN (PRN) se sospecha que evaden la inmunidad inducida por la vacuna o alteran la gravedad de la enfermedad; en un reciente estudio realizado por Martin y et al. Se evaluó de manera retrospectiva la asociación entre la producción de pertactina $\left(\mathrm{PRN}^{-}, \mathrm{PRN}+\right.$ ), la presentación clínica de la enfermedad y el historial vacunal; el $85 \%$ de los aislados fueron PRN; se concluyó que existe una asociación significativa entre la inmunización y la producción $\mathrm{PRN}^{+}$, lo cual sugiere que la probabilidad de que se haya desarrollado la enfermedad causada por las cepas PRN es mayor en los pacientes vacunados (80).

En estudios recientes, han utilizado formulaciones de proteoliposomas de B. pertussis (PLBp), toxoide tetánico y difteria (DT-PLBpI), evaluándose como vacuna trivalente candidata en ratones BALB/c; con lo cual se evidenció una reducción total de UFC a nivel pulmonar a los 7 días después del inoculado intranasal de B. pertusis, además de inducir la producción de anticuerpos $>2 \mathrm{UI} / \mathrm{mL}$ contra tétano y difteria (81).

Los proteoliposomas son estructuras vesiculares nanoparticuladas que contienen proteínas, lípidos y lipopolisacáridos nativos (LPS), gracias a sus propiedades inmunoestimulantes y adyuvantes, las hacen moléculas atractivas para el desarrollo de vacunas contra varias enfermedades (82).

En la actualidad, las vacunas acelulares contra la tos ferina no proporcionan una inmunidad protectora adecuada y estudios demuestran cambios significativos en las poblaciones de $\mathrm{B}$. pertussis, lo que sugiere la adaptación, la persistencia y el resurgimiento bacteriano frente a la evasión de la presión ocasionada por las vacunas; estos cambios incluyen divergencia antigénica con las cepas vacunales y el aumento en la producción de toxina pertussis; la divergencia antigénica afecta principalmente la memoria inmune y la eficacia de los anticuerpos, mien- 
tras que los niveles altos de la toxina pueden aumentar la supresión del sistema inmune innato y adquirido (83-85).

Finalmente, debe considerarse la contribución de los cambios genéticos de las cepas circulantes de B. pertussis, a la enfermedad; es claro que éstos han ocurrido en diferentes antígenos bacterianos, los cuales han llevado a que el microorganismo eluda la inmunidad inducida por la vacuna o sea más virulento; dichos cambios pueden atribuirse a la presión selectiva ejercida por la vacuna a lo largo del tiempo. Estudios genéticos demuestran pérdida de regiones en el genoma de diferentes cepas circulantes; de acuerdo con esto, en un trabajo realizado por Kallonen y et al. en el 2011, se encontraron diferencias en el contenido genómico de $B$. pertussis aislada antes y después de la introducción de la vacuna contra la tos ferina en cuatro países europeos; mediante técnicas moleculares, los autores compararon el genoma de 39 cepas vacunales y aislados clínicos antiguos colectados de los diferentes países, observando pérdida de tres regiones genómicas en los aislados analizados, además de describir un nuevo alelo promotor de la toxina pertusis (ptxP3), que reemplazó los aislados con el alelo ptxP1 en los países evaluados; dichos hallazgos demuestran que las cepas circulantes en Europa en la época pre-vacunal y sus genomas eran distintos a las cepas de referencia correspondiente a los aislados recientes, lo que sugiere que dichas diferencias genómicas podrían deberse a la presión inducida por la introducción de la vacuna (86).

Como lo han demostrado otros estudios, se ha producido una pérdida progresiva de genes en los aislamientos $B$. pertussis, en países como Finlandia, posterior al inicio de la vacunación contra la tos ferina en dicho país desde 1952; los resultados de dichos estudios confirman que las cepas circulan de manera dinámica y evolucionan continuamente, lo que sugiere que la bacteria puede usar la pérdida de genes como una estrategia para adaptarse a poblaciones altamente imnunizadas (87).

En una investigación reciente se compararon los reordenamientos en el genoma entre 257 aislados de B. pertussis para evaluar la estructura cromosomal, en la cual se identificaron cambios discretos que diferenciaron el genoma de las cepas de referencia de la vacuna y varios aislados clínicos; entre los reordenamientos observados fueron principalmente grandes inversiones centrados en el origen de replicación y flanqueados por un elemento genético móvil > 240 copias por genoma (IS481), y previamente reportado como mediador de reordenamientos y deleciones por recombinación homóloga; dichos datos sugieren que la evolución del genoma estructural de $B$. pertussis no se limita a la pérdida de regiones en el genoma, sino que también incluye reordenamientos, y aunque los genomas de los aislamientos clínicos se evidencia heterogeneidad estructural, se conservan cambios específicos en el orden de los genes, posiblemente debido a la selección positiva, lo que proporciona información novedosa para futuras investigaciones en el resurgimiento de la enfermedad (88)

Hacia un futuro, con la ayuda de técnicas moleculares, de proteómica y metabolómica, se pretende dar un enfoque más integrado del problema, incluyendo las características de las vacunas, las poblaciones de $B$. pertussis y la interacción entre éstas.

\section{Discusión}

Después de la exposición a $B$. pertussis, la patogenia de la enfermedad depende de cuatro etapas: fijación, evasión de defensas del huésped, daño local y enfermedad sistémica. La aparición de la enfermedad, que implica la unión al epitelio respiratorio, la existencia de lesiones locales y la absorción sistémica de toxinas depende de la alteración y desaparición de los mecanismos de defensa del huésped (cilios y neutrófilos). Está claramente demostrado que la vacunación no proporciona protección para toda la vida contra la tos ferina $(89,90)$.

Estudios recientes demuestran que la citotoxina traqueal, el factor dermonecrótico y la adenilato ciclasa, son en su mayoría las responsables del daño epitelial local que da lugar a los síntomas respiratorios y facilita la absorción de la Toxina Pertussis, que a su vez posee numerosas actividades biológicas, sensibilidad a la histamina, la secreción de insulina, la disfunción leucocitaria y otras, algunas de las cuales pueden explicar las manifestaciones sistémicas de la enfermedad.

La clínica de la tos ferina es diferente en adolescentes respecto a los lactantes, aunque en general es menos grave, también se observan casos graves y complicaciones. Una tos persistente puede ser el único sintoma, tos de más de 4 semanas de evolución, tos nocturna o que se exacerba al comer o beber es igualmente típico en adolescentes $(91,92)$.

Para el desarrollo de nuevas vacunas contra la tos ferina, múltiples estudios han realizado aportes que permitan una vacuna más eficiente, y entre las características más importantes para su desarrollo, al igual que para cual- 
quier otra vacuna, se encuentran: 1) inducir un patrón de respuesta inmunitaria similar a la infección natural, 2) mostrar un perfil reactogénico mejor que las vacunas tradicionales, 3) ser multi-antigénicos con el fin de eludir la presión de la vacuna, 4) ser asequible tanto para los países desarrollados como para los países en desarrollo (93).

Actualmente se le da mucho valor al criterio clínico de tos ferina ya que la confirmación debe realizarse con métodos auxiliares de diagnóstico como el cultivo o la reacción en cadena de la polimerasa (PCR), no siempre disponible (93).

\section{Conflicto de Intereses}

Los autores del presente manuscrito declaran no tener conflicto de intereses

\section{Financiación}

Ninguna

\section{Referencias}

1. Campins M, Moreno D, Gil A, González F, Moraga FA, Arístegui J, et al. Whooping cough in Spain. Current epidemiology, prevention and control strategies. Recommendations by the Pertussis Working Group. Enferm Infecc Microbiol Clin. 2013; 31(4):240-53. DOI: 10.1016/j.eimc.2012.12.011.

2. Departamento de Salud y Hospitales de Louisiana, Oficina de Salud Pública, sección de Epidemiología de Enfermedades Infecciones, 2011.

3. Paddock CD, Sanden GN, Cherry J. Pathology and pathogenesis of Bordetella pertussis infection in infants. Clin Infect Dis. 2008; 47:328-38.

4. WHO Challenges in global immunization and the Global Immnunization Vision and Strategy 20062015. Weekly Epidemiol Rec. 2007; 87:190-5.

5. Versteegh FG, Mooi-Kokenberg EA, Schellekens JF, Roord JJ. Bordetella pertussis and mixed infections. Minerva Pediatr. 2006; 58:131-7. PMID:16835573

6. Hewlett EL, Edwards KM. Clinical practice. Pertussisnot just for kids. N Engl J Med. 2005; 352:1215-1222. DOI: 0.1056/NEJMcp041025

7. Ledermann $W$. Brief history about Bordetella pertussis, an elusive mademoiselle. Rev Chil Infect. 2004; 21(3): 241-246. http://dx.doi. org/10.4067/S0716-10182004000300018

8. Informe de la reunión de octubre de 1988. The Tokai J. of Exp. Clin. Med., 1989. Copenhage 22-26 de octubre 1988.

9. Wardlaw A, Parton R. Pathogenesis and inmuni- ty in Pertussis, John Wiley and Sons, 1988. ISBN 0471918202,9780471918202

10. World Health Organization. Pertussis vaccines: WHO position paper - September 2015. Wkly Epidemiol Rec. 2015; 90:433-58.

11. Kmietowicz Z. Pertussis cases rise 10-fold among older children and adults in England and Wales. BMJ 2012; 345:e5008. DOI: 10.1136/bmj.e5008.

12. Pillsbury A, Quinn HE, McIntyre PB. Australian vaccine preventable disease epidemiological review series: pertussis, 2006-2012. Commun Dis Intell Q Rep 2014; 38(3):E179-94. PMID: 25391404

13. Urbiztondo L, Broner S, Costa J, Rocamora L, Bayas J, Campis M, et al., Seroprevalence study of B. pertussis infection in health care workers in Catalonia, Spain. Hum Vaccin Immunother. 2015; 11(1):293-297. DOI: 10.4161/hv.36167

14. Cherry. Epidemic Pertussis in 2012 - the Resurgence of a Vaccine-Preventable Disease. N Engl J Med. 2012; 367:785-787. DOI: 10.1056/NEJMp1209051

15. Centers for Disease Control and Prevention. Notice to readers: final 2012 reports of nationally notifiable infectious diseases. MMWR Morb Mortal Wkly Rep. 20136266982

16. Fedele G, Stefanelli P. Pertussis in infants and the resurgence of a vaccine preventable disease: what to do? Ann Ist Super Sanità. 2017; 53(2):100-103. DOI: 10.4415/ANN_17_02_04.

17. Forsyth K, Plotkin S, Tan T, Wirsing von Koning. Strategies to decrease pertussis transmission to infants. $\mathrm{Pe}$ diatrics. 2015; 135:e1475-e1482. DOI: 10.1542/ peds.2014-3925.

18. Hewlett EL, Edwards KM. Clinical practice. Pertussisnot just for kids. N Engl J Med. 2005; 352:1215-1222. DOI: 0.1056/NEJMcp041025

19. Oksuz L, Gurler N, Aqacfidan A. Investigation of seropositivity of Bordetella pertussis in adults in a university hospital. Mikrobiyol Bul. 2017; 51(1):62-72 PMID: 28283011

20. Maltezou HC, Ftika L, Theodoridou M. Nosocomial pertussis in neonatal units. J Hosp Infect. 2013; 85(4):243-248. doi: 10.1016/j.jhin.2013.09.009

21. Yin H, Ching S, Tay J, Chieh Y, Yin L, Lan P, et al. Lack of pertussis-protective antibodies in healthcare providers taking care of neonates and infants in a children's hospital. The Pediatric Infectious Disease Journal. 2017; 36(4):433-435

22. Kurehong C, Kanchanawarin C, Powthongchin B, Katzenmeier G, Angsuthanasombat C. Membrane-Pore Forming Characteristics of the Bordetella pertussis CyaA-Hemolysin Domain. Toxins 2015, 7, 1486-1496; doi:10.3390/toxins7051486

23. Yesmin K, Mamun KZ, Shamsazzaman SM, Chowdhury A, Khatun K, Alam J. Isolation of potential pathogenic bacteria from nasopharynx from patients having cough for more than two weeks. Bangladesh J Med Microbiol. 2010; 4:13-18. 
24. Michigan Center for Public Health Preparedness. Basic reproductive rate $\left(\mathrm{R}_{0}\right)$. University of Michigan, School of Public Health, Office of Public Health Practice, Ann Arbor, MI. 2010. https://practice.sph.umich.edu/ micphp/epicentral/basic_reproduc_rate.php

25. Kretzschmar M, Teunis PF, Pebody RG. Incidence and reproduction numbers of pertussis: estimates from serological and social contact data in five European countries. PLoS Med. 2010. 7:e1000291. http://dx.doi .org/10.1371/journal.pmed.1000291.

26. Kilgore P. Salim A, Zervos M, Schmitt H. Pertussis: Microbiology, disease, treatment, and prevention. Clinical Microbiology Reviews. 2016; 29(3): 499-86. doi:10.1128/CMR.00083-15.

27. Instituto Nacional de Salud. Protocolo de Vigilancia en Salud Pública. Tos ferina. 2014.

28. Heininger U, Stehr K, Cherry JD. Serious pertussis overlooked in infants. Eur J Pediatr. 1992; 151:342343. http://dx.doi.org/10.1007/BF02113254.

29. Centers for Disease Control and Prevention. Pertussis (Whooping Cough). Enero 2017. https://www.cdc. gov/pertussis/about/signs-symptoms.html

30. Centers for Disease Control and Prevention. Bordetella pertussis. 2017. https://www.cdc.gov/vaccines/pubs/ pinkbook/downloads/pert.pdf

31. Cornia PB, Hersh AL, Lipsky BA, Newman TB, Gonzales $\mathrm{R}$. Does this coughing adolescent or adult patient have pertussis? JAMA. 2010; 304:890-896. http:// dx.doi.org/10.1001/jama.2010.1181.

32. Higgs R, Higgins S, Ross P, Mills K. Immunity to the respiratory pathogen Bordetella pertussis. Mucosal Immunology. 2012; 5(5):485-500; DOI:10.1038/ mi.2012.54

33. Gouw D, Diavatopoulos DA, Bootsma HJ, Hermans PW, Mooi FR. Pertussis: a matter of immune modulation. FEMS Microbiol Rev. 2011; 35(3):441-74. DOI: 10.1111/j.1574-6976.2010.00257.x.

34. Carbonetti N. Pertussis toxin and adenylate cyclase toxin: key virulence factors of Bordetella pertussis and cell biology tools. Future Microbiol. 2010; 5:455-469. DOI: $10.2217 /$ fmb.09.133.

35. Weingart Ch, Weiss A. Bordetella pertussis Virulence Factors Affect Phagocytosis by Human Neutrophils. Infect Immun. 2000; 68(3):1735-1739. PMCID: PMC97341 PUBMED

36. Schneider O, Weiss A, Miller W. Pertussis toxin utilizes proximal components of the $\mathrm{T}$-cell receptor complex to initiate signal transduction events in T cells. Infect. Immun. 2007; 75(8):4040-4049. DOI:10.1128/ IAI.00414-07

37. Bagley K, Abdelwahab S, Tuskan R, Fouts T, Lewis G. Pertussis toxin and the adenylate cyclase toxin from Bordetella pertussis activate human monocyte-derived dendritic cells and dominantly inhibit cytokine production through a cAMP-dependent pathway. Journal of Leukocyte Biology. 2002; 72(5):962-69. PMID: 12429718
38. Kamanova J. Kofronova O, Masin J, Genth H, Vojtova $\mathrm{J}$, Linhartova I, et al. Adenylate cyclase toxin subverts phagocyte function by RhoA inhibition and unproductive ruffling. J. Immunol. 2008; 181(8): 5587-5597. PMID: 18832717

39. Boyd A, Ross P, Conroy H, Mahon N, Lavelle E, Mills K. Bordetella pertussis adenylate cyclase toxin modulates innate and adaptive immune responses: distinct roles for acylation and enzymatic activity in immunomodulation and cell death. J. Immunol. 2005; 175(2):730738. PMID: 16002668

40. Gray M, Szabo G, Otero A, Gray L, Hewlett E. Distinct mechanisms for $\mathrm{K}+$ efflux, intoxication, and hemolysis by Bordetella pertussis AC toxin. J. Biol. Chem. 1998; 273(29):18260-18267. PMID: 9660789

41. Donato G, Goldsmith C, Paddock C, Eby J, Gray M, Hewlett E. Delivery of Bordetella pertussis adenylate cyclase toxin to target cells via outer membrane vesicle. FEBS Letters. 2012; 586(4): 459-465. . https://doi. org/10.1016/j.febslet.2012.01.032.

42. Chenal A, Karst CJ, Sotomayor CA, Wozniak KA, Baron B, England P, Ladant D. Calcium-Induced Folding and Stabilization of the Intrinsically Disordered RTX Domain of the CyaA Toxin. Biophysical Journal. 2010; 99(11): 3744-3753 DOI: 10.1074/jbc.M807312200

43. Rivero Y, Fando R. La toxina adenilato ciclasa-hemolisina de Bordetella pertussis: función en la patogénesis y aplicaciones. Revista CENIC. Ciencias Biológicas. 2013; 44(3):44-56.

44. Linhartová I, Bumba L, Mašín J, Basler M, Osička R, Kamanová J. RTX proteins: a highly diverse family secreted by a common mechanism. FEMS Microbiol Rev. 2010; 34(6):1076-112. Doi: 10.1111/j.15746976.2010.00231. x.

45. Hewlett EL, Gray L, Allietta M, Ehrmann I, Gordon VM, Gray MC J. Adenylate cyclase toxin from Bordetella pertussis. Conformational change associated with toxin activity. Biol Chem. 1991; 266(26):17503-8. PMID: 1894634.

46. Rivero Y, Fando R. La toxina adenilato ciclasa-hemolisina de Bordetella pertussis: función en la patogénesis y aplicaciones. Revista CENIC. Ciencias Biológicas. 2013; 44(3):44-56.

47. Cannella S, Ntsogo V, Davi M, Malosse C, Sotomayor A, Chamot J. Et al. Stability, structural and functional properties of a monomeric, calcium-loaded adenylate cyclase toxin, CyaA, from Bordetella pertussis. Sci Rep. 2017; 7: 42065. DOI: 10.1038/srep42065

48. Basler M, Masin J, Osicka R, Sebo P. Pore-Forming and Enzymatic Activities of Bordetella pertussisAdenylate Cyclase Toxin Synergize in Promoting Lysis of Monocytes. Infect Immun. 2006; 74(4):2207-14. DOI: 10.1128/IAI.74.4.2207-2214.2006

49. Rogel A, Hanski E. Distinct steps in the penetration of adenylate cyclase toxin of Bordetella pertussis into sheep erythrocytes. The Journal of biological chemistry. 1992; 267(31);22599-605. PMID:1429610 
50. Guermonprez P, Khelef N, Blouin E, Rieu P, Ricciardi-Castagnoli P, Guiso N, et al. The adenylate cyclase toxin of Bordetella pertussis binds to target cells via the alpha(M) beta (2) integrin (CD11b/CD18). J Exp Med. 2001; 193(9):1035-44. PMCID: PMC2193436

51. Eby J, Ciesla W, Hamman W, Donato GM, Pickles RJ, Hewlett EL, Lencer WI. Selective translocation of the Bordetella pertussis adenylate cyclase toxin across the basolateral membranes of polarized epithelial cells. J Biol Chem. 2010; 285(14):10662-70. DOI: 10.1074/ jbc.M109.089219.

52. Gentile F, Raptis A, Knipling LG, Wolff J. Bordetella pertussis adenylate cyclase. Penetration into host cells. Eur J Biochem. 1988; 175(3):447-53. PMID: 2900763

53. Basler M, Knapp O, Masin J, Fiser R, Maier E, Benz $\mathrm{R}$, et al. Segments Crucial for Membrane Translocation and Pore-forming Activity of Bordetella Adenylate Cyclase. J Biol Chem 2007; 282(17):12419-12429. DOI:10.1074/jbc.M611226200

54. Osickova A, Masin J, Fayolle C, Krusek J, Basler M, Pospisilova E, et al. Adenylate cyclase toxin translocates across target cell membrane without forming a pore. Molecular Microbiology. 2010; 75(6):1550-1562. DOI:10.1111/j.1365-2958.2010. 07077.x

55. Njamkepo E, Pinot F, François D, Guiso N, Polla BS, Bachelet $\mathrm{M}$. Adaptive responses of human monocytes infected by Bordetella pertussis: the role of adenylate cyclase hemolysin. J Cell Physiol. 2000; 183(1):91-9. DOI: 10.1002/(SICI)10974652(200004)183:1<91:AID-JCP11>3.0.CO;2-S.

56. Ladant D, Ullmann A. Bordatella pertussis adenylate cyclase: a toxin with multiple talents. Trends Microbiol. 1999; 7(4):172-176. PMID: 10217833.

57. Melvin J, Scheller E, Noel Ch, Cotter P. New Insight into Filamentous Hemagglutinin Secretion Reveals a Role for Full-Length FhaB in Bordetella Virulence. MBio. 2015; 6(4): e0118915. DOI: 10.1128/mBio.01189-15

58. Locht C, Bertin P, Menozzi F, Renauld G. The filamentous haemagglutinin, a multifaceted adhesion produced by virulent Bordetella spp. Mol. Microbiol. 1993; 9(4):653-660. PMID: 8231801

59. McGuirk P, Mills K. Direct anti-inflammatory effect of a bacterial virulence factor: IL-10-dependent suppression of IL-12 production by filamentous hemagglutinin from Bordetella pertussis. Eur. J. Immunol. 2000; 30(2):415422. DOI: $10.1002 / 1521-4141(200002) 30: 2<415$ : AID-IMMU415>3.0.CO;2-X.

60. Leininger E, Roberts M, Kenimer JG, Charles IG, Fairweather N, Novotny P, Brennan MJ. Pertactin, an Arg-Gly-Asp-containing Bordetella pertussis surface protein that promotes adherence of mammalian cells. Proc Natl Acad Sci U S A. 1991; 88(2):345-9. PMCID: PMC50807

61. Hijnen M, Mooi F, van Gageldonk P, Hoogerhout P, King A, Berbers G. Epitope structure of the Bordetella pertussis protein P.69 pertactin, a major vaccine component and protective antigen. Infect. Immun. 2004;
72(7):3716-3723. DOI:10.1128/IAI.72.7.37163723.2004

62. Bouchez V, Brun D, Cantinelli T, Dore G, Njamkepo E, Guiso N. First report and detailed characterization of $B$. pertussis isolates not expressing Pertussis Toxin or Pertactin. Vaccine. 2009; 27(43):6034-41. DOI: 10.1016/j.vaccine.2009.07.074

63. Zeddeman A, van Gent M, Heuvelman CJ, van der Heide HG, Bart MJ, Advani A. Investigations into the emergence of pertactin-deficient Bordetella pertussis isolates in six European countries, 1996 to 2012. Euro Surveill. 2014; 19(33): pii: 20881. PMID: 25166348

64. Miyaji Y, Otsuka N, Toyoizumi-Ajisaka H, Shibayama K, Kamachi K. Genetic analysis of Bordetella pertussis isolates from the 2008-2010 pertussis epidemic in Japan. PLoS One. 2013; 8(10):e77165. DOI: 10.1371/ journal.pone.0077165.

65. Yukihiro Hiramatsu, Yusuke Miyaji, Nao Otsuka, Yoshichika Arakawa, Keigo Shibayama, Kazunari Kamachi. Significant Decrease in Pertactin-Deficient Bordetella pertussis Isolates, Japan. Emerg Infect Dis. 2017; 23(4):699-701. DOI: 10.3201/eid2304.161575

66. Carbonetti N, Artamonova G, Van Rooijen N, Ayala $\mathrm{V}$. Pertussis toxin targets airway macrophages to promote Bordetella pertussis infection of the respiratory tract. Infect. Immun. 2007; 75(4):1713-1720. DOI:10.1128/IAI.01578-06

67. Weingart Ch, Weiss A. Bordetella pertussis Virulence Factors Affect Phagocytosis by Human Neutrophils. Infect Immun. 2000; 68(3):1735-1739. PMCID: PMC97341.

68. Higgins S, Lavelle E, McCann C, Keogh B, McNeela E, Byrne $\mathrm{P}$, et al. Toll-like receptor 4-mediated innate IL-10 activates antigen-specific regulatory $\mathrm{T}$ cells and confers resistance to Bordetella pertussis by inhibiting inflammatory pathology. J. Immunol. 2003; 171:3119-3127. PMID: 12960338

69. Ryan M, Murphy G, Ryan E, Nilsson L, Shackley F, Gothefors L, et al. Distinct T-cell subtypes induced with whole cell and acellular pertussis vaccines in children. Immunology. 1998; 93(1):1-10. PMCID: PMC1364099.

70. Ye P, Rodriguez FH, Kanaly S, Stocking KL, Schurr $\mathrm{J}$, Schwarzenberger $\mathrm{P}$, et al. Requirement of interleukin 17 receptor signaling for lung $\mathrm{CXC}$ chemokine and granulocyte colony-stimulating factor expression, neutrophil recruitment, and host defense. J Exp Med. 2001; 194(4):519-27. PMCID: PMC2193502

71. Ross P, Sutton C, Higgins S, Allen A, Walsh K, Misiak A, et al. Relative Contribution of Th1 and Th17 Cells in Adaptive Immunity to Bordetella pertussis: Towards the Rational Design of an Improved Acellular Pertussis Vaccine. PLoS Pathog. 2013; 9(4):e1003264. DOI: 10.1371/journal.ppat. 1003264

72. Hernández J, Urcuqui S. Activación y regulación de inflamasoma NLRP3 en las enfermedades infecciosas. Iatreia. 2012; 25(4):380-390.

73. Li H, Willingham SB, Ting JP, Re F. Cutting edge: inflammasome activation by alum and alum's adjuvant effect are mediated by NLRP3. J Immunol. 2008; 181(1):17-21. PMCID: PMC2587213 
74. WHO. Immunization, Vaccines and Biologicals. Manual for Quality Control of Difteria, Tetanus and Pertussis vaccines. 2013.

75. Morel S, Denoel P, Godfroid F, Cortvrindt C, Vanderheyde N, Poolman J. Induction of Bordetella pertussis -specific immune memory by DTPa vaccines. Vaccine. 2011; 29(18):3449-55. https://doi.org/10.1016/j. vaccine.2011.02.062

76. Masin J, Osicka R, Bumba L, Sebo P. Bordetella adenylate cyclase toxin: a unique combination of a pore-forming moiety with a cell-invading adenylate cyclase enzyme. FEMS Pathogens and Disease, 2015; 73(8): ftv075. doi: 10.1093/femspd/ftv075.

77. Gustafsson L, Hallander H, Olin P, Reizenstein E, Storsaeter J. A controlled trial of a two-component acellular, a five-component acellular, and a whole-cell pertussis vaccine. N Engl J Med 1996; 334:349-356. DOI: 10.1056/NEJM199602083340602

78. Hegerle N, Dore G, Guiso N. Pertactin deficient Bordetella pertussis present a better fitness in mice immunized with an acellular pertussis vaccine. Vaccine. 2014; 32(49):6597-600. https://doi.org/10.1016/j. vaccine.2014.09.068

79. Hegerle N, Guiso N . Antibody-mediated inhibition of Bordetella pertussis adenylate cyclase-haemolysin-induced macrophage cytotoxicity is influenced by variations in the bacterial population. Microbiology. 2014; 160(5):962-9. DOI: 10.1099/mic.0.074690-0.

80. Martin S, Pawloski L, Williams M, Weening K, DeBolt Ch, et al. Pertactin-Negative Bordetella pertussis Strains: Evidence for a Possible Selective Advantage. Clin Infect Dis. 2015; 60(2):223-227. DOI: https:// doi.org/10.1093/cid/ciu788.

81. Fernández S, Landys M, Gutiérrez N, Corcho L, Blanco A, Serrano D, et al., A Bordetella pertussis proteoliposome induces protection in mice without affecting the immunogenicity of diphtheria and tetanus toxoids in a trivalent formulation. Clin Exp Vaccine Res. 2016; 5(2):175-8. DOI: 10.7774/cevr.2016.5.2.175.

82. Fernandez S, Fajardo EM, Mandiarote A, Gemma A, Padrón M, Acosta M, et al. A proteoliposome formulation derived from Bordetella pertussis induces protection in two murine challenge models. BMC Immunol. 2013; 14(1): S8. DOI: $10.1186 / 1471-2172-14-S 1-S 8$

83. Mooi F, Van Der Maas N, De Melker H. Pertussis resurgence: waning immunity and pathogen adaptation - two sides of the same coin. Epidemi- ol Infect. 2014; 142(4):685-94. DOI: 10.1017/ S0950268813000071.

84. Octavia S, Maharjan R, Sintchenko V, Stevenson G, Reeves P, Gilbert G, Lan R. Insight into evolution of Bordetella pertussis from comparative genomic analysis: evidence of vaccine-driven selection. Molecular Biology and Evolution. 2011; 28(1):707-715. doi: $10.1093 / \mathrm{molbev} / \mathrm{msq} 245$.

85. M van Gent, Bart M, van der Heide, Heuvelman K, Mooi F. Small mutations in Bordetella pertussis are associated with selective sweeps. PLoS One. 2012; 7(9): e46407. doi: 10.1371/journal.pone.0046407.

86. Kallonen T, Grondahl K, Elomaa A, Lutynska A, Fry N, Mertsola J, He Q. Differences in the genomic content of Bordetella pertussis isolates before and after introduction of pertussis vaccines in four European countries. Infect Genet Evol. 2011; 11(8):2034-42. doi: 10.1016/j.meegid.2011.09.012.

87. Heikkinen E, Kallonen T, Saarinen L, Sara R, King A.J, Mooi F, et al. Comparative genomics of Bordetella pertussis reveals progressive gene loss in Finnish strains. PLoS ONE. 2007; 19; 2(9): e904. DOI: 10.1371/ journal.pone.0000904.

88. Weigand M, Peng Y, Loparev V, Batra D, Bow den K, Burroughs $\mathrm{M}$, et al. The History of Bordetella pertussis Genome Evolution Includes Structural Rearrangement. J Bacteriol. 2017; 199(8). pii: e00806-16. DOI: 10.1128/JB.00806-16

89. Minh N.N.T., He Q., Ramalho A., Kaufhold A., Viljanen M., Arvilommi H., et al: Acellular vaccines containing reduced quantities of pertussis antigens as a booster in adolescents. Pediatrics 1999; 104: pp. e70

90. Gentile A. Infección por Bordetella pertussis. Arch Argent Pediatr. 2010; 108(1):78-81.

91. Manual Para el diagnóstico de Bordetella pertussis/ Bordetella parapertussis. Diagnóstico de laboratorio de la tos ferina. IPK. La Habana: MINSAP; 2010.

92. Word Health Organizartion. WHO Vaccine Assessment and Monitoring team of the Department of Vaccines and Biologicals. WHO-recommended standards for surveillance of selected vaccine-preventable diseases. Geneva: WHO; 2013.

93. Word Health Organization. WHO Challenges in global immunization and the Global Immnunization Vision and Strategy. Weekly Epidemiol Rec. 2015; 87:190-5. 